\title{
Digital Technology in Mathematics Education: Research over the Last Decade
}

\author{
Marcelo C. Borba, Petek Askar, Johann Engelbrecht, \\ George Gadanidis, Salvador Llinares and Mario Sánchez Aguilar
}

\begin{abstract}
In this survey paper we focus on identifying recent advances in research on digital technology in the field of mathematics education. We have used Internet search engines with keywords related to mathematics education and digital technology and have reviewed some of the main international journals. We identify five sub-areas of research, important trends of development, and illustrate them using case studies: mobile technologies, massive open online courses (MOOCs), digital libraries and designing learning objects, collaborative learning using digital technology, and teacher training using blended learning. These exemplary case studies may help the reader to understand how recent developments in this area of research have evolved in the last few years. We conclude the report discussing some of the implications that these digital technologies may have for mathematics
\end{abstract}

This paper is a shortened version of the paper by Borba, Askar, Engelbrecht, Gadanidis, Llinares, and Sánchez Aguilar (2016).

M.C. Borba

UNESP, Rio Claro, Brazil

e-mail: mborba@rc.unesp.br

P. Askar

Hacettepe University, Ankara, Turkey

e-mail: petek.askar@gmail.com

J. Engelbrecht $(\square)$

University of Pretoria, Pretoria, South Africa

e-mail: johann.engelbrecht@up.ac.za

G. Gadanidis

Western University, London, ON, Canada

e-mail: ggadanid@uwo.ca

S. Llinares

Universidad de Alicante, Alicante, España

e-mail: sllinares@ua.es

M.S. Aguilar

Instituto Politécnico Nacional, Mexico City, Mexico

e-mail: mosanchez@ipn.mx

(C) The Author(s) 2017

G. Kaiser (ed.), Proceedings of the 13th International Congress on Mathematical

Education, ICME-13 Monographs, DOI 10.1007/978-3-319-62597-3_14 
education research and practice as well as making some recommendations for future research in this area.

Keywords Internet - Mobile learning - MOOC - Blended learning - Digital libraries $\cdot$ Learning objects $\cdot$ Collaborative learning

\section{Introduction}

Digital technology has changed the very notion of what being a human means.

Assertions such as the one above can be found in the literature at large. The idea that innovative media tools we use condition our thinking is not new and consequently should not be surprising. McLuhan (1964) determined this link several decades ago with his often-quoted assertion that "the medium is the message". Mobility, online courses, massive open online courses (MOOCs) and touch technology are terms that are part of our lives as mathematics educators, and many of these terms are part of the daily lives of $45 \%$ of the world population that has access to the Internet.

Research struggles to keep up with the pace of change in the world of digital technology. We like to determine identifiable phases in the development of using digital technology in mathematics education. The first phase commenced with the introduction of Logo as a teaching tool. Academics began to research its use and impact, but before we knew it, "content" software such as Cabri or Geometer's Sketchpad became available. We had not yet solved all the problems from this first phase of digital technology in mathematics education (Borba, Scucuglia, \& Gadanidis, 2014), when the second phase arrived with new notions such as dragging, that allowed students to "experiment mathematics". Again, we were still trying to understand the role of computer laboratories in schools, a novelty from both the first and second phases (depending on the country), when the Internet showed up.

We shift our focus from microworlds, to modelling, to computer laboratories, and now to the relationship revolution (Schrage, 2001), afforded by online tools, which we refer to as the third phase. This phase, characterized by the Internet, brings us communication changes that dramatically alter the way we relate to one another. This creates new research problems to be addressed (Engelbrecht \& Harding, 2005a, b; Borba, Malheiros, \& Zulatto, 2010) and prompted us to include collaborative learning using technology as one of the current trends of development. In mathematics education, the way the Internet can be used in a blended learning environment characterizes the third phase, which introduces online courses and new problems.

Quantitative change in the Internet has generated a change in quality, and expressions such as Web 2.0 and broadband Internet indicate that a new Internet has developed over the last 5-10 years. This new phase, which we are experiencing 
now and refer to as the fourth phase, brings us massive open online courses (MOOCs) — another trend of development, enhanced opportunities for collaborative learning, and the personalization of the Internet through personal devices. This phase also opens new opportunities for storing digital information through the massive increases in storage and computing power, and the emergence of cloud computing; it is in this context that digital libraries appear as another trend of development. Along with these developments, a move to mobile technology introduces new possibilities in the teaching of mathematics and leads to a further prominent development trend, included in our discussion.

From the discussion above we see that five prominent trends of development were identified. In this paper we attempt to contribute to the goal of surveying this changing area in a particular way, in that we focus on these five important sub-areas of current research, reporting developments related to mobile technologies, massive open online courses (MOOCs), digital libraries and designing learning objects, collaborative learning using digital technology, and teacher training using blended learning.

\section{Methodology}

Several publications have attempted to survey this emerging and always-changing area of digital technologies in mathematics education. Eight chapters on digital technology in the Third International Handbook of Mathematics Education (Clements, Bishop, Keitel, Kilpatrick, \& Leung, 2013), and the special issue of ZDM on online distance education (Borba \& Llinares, 2012) are examples of such publications. These publications attempt to organize the field of research in order to do what Bicudo (2014) calls meta-analysis.

To develop the survey we relied on three sources of information: (1) international research journals, including journals in Portuguese and Spanish, (2) Internet search engines with keywords related to mathematics education and digital technology and (3) the knowledge of the authors of this article about the surveyed areas.

\section{Trends of Development}

D'Ambrosio and Borba (2010) consider trends of development, such as the use of digital technology in mathematics education, as a response to problems within the region of inquiry in mathematics education. The on-going concerns show that this trend is still growing. But to what problem does this sub-area of investigation respond? It seems that all phases of attempts to introduce digital technology have faced problems related to displacing embedded rules of time and space that we were not aware of when we experienced the "paper-and-pencil" classroom. 
We do not claim to present a comprehensive survey of papers, even though we have highlighted a few in each of the chosen categories. We focus on describing five cases of mathematics education in which digital technology is used in different ways.

\section{Use of Mobile Technologies in Mathematics Teaching and Learning}

The use of mobile technologies (such as smartphones and tablets) in the teaching and learning of mathematics is gaining a growing interest among educational researchers and practitioners. The characteristics of mobile devices such as portability, availability, access to the Internet, and its wide acceptance among young people and others, have made mobile devices an emerging agent capable of expanding the frontiers of mathematics instruction and learning beyond the walls of the classroom. White and Martin (2014, p. 64) argue that the characteristics of mobile devices (such as capturing and collecting information, communicating and collaborating with others, consuming and critiquing media, constructing and creating personal forms of representation and expression) can be readily mapped onto mathematical, scientific, and engineering practices highlighted in the Common Core Math and Next Generation Standards (NGSS Lead States, 2013).

Research on the possible uses and potentialities of mobile technologies is growing, but in mathematics education, research on this topic is still limited. Nevertheless, we can find research reports (e.g. Crompton \& Traxler, 2015; Larkin \& Calder, 2015) addressing how this kind of technology could be used in the teaching and learning of mathematics.

Early studies of mobile learning in mathematics date from shortly before 2010 (e.g. Franklin \& Peng, 2008), and since then we have witnessed a growth in this type of research, both at international conferences and in specialized journals. Most of the literature reviewed for this survey can be divided into three broad categories: (a) studies on the potential of mobile devices for teaching and learning mathematics; (b) affective studies on the use of mobile devices; and (c) use of mobile devices in mathematics teacher education.

(a) Studies on the potential of mobile devices for teaching and learning mathematics

Several studies have focused on exploiting the capabilities of mobile technologies, like portability, mobility, and the capacity to take photos and videos of real phenomena that later can be analyzed and discussed from a mathematical point of view. An example is the work of Wijers, Jonker, and Drijvers (2010), who used a location-based game called MobileMath for mobile phones with GPS to allow students to create and explore quadrilaterals and their properties on a real playing field outside the classroom. 


\section{(b) Affective studies on the use of mobile devices}

Some studies have focused on studying the perceptions and emotions that mathematics teachers and students experience when they teach or study mathematics by using mobile devices. For example, Holubz (2015) studied the perceptions of students and teachers about an initiative called "Bring Your Own Device" (BYOD), where the use of the Internet and mobile devices for the study of mathematics is promoted.

\section{(c) Use of mobile devices in mathematics teacher education}

Finally, we note that a few studies analyse the use of mobile devices in mathematics teacher education. Yerushalmy and Botzer (2011), for instance, discuss theoretical considerations as well as challenges and opportunities underlying the design of inquiry tasks in mobile settings for pre-service and in-service teachers.

As an example that illustrates how mobile devices can be used to promote the learning of mathematical concepts, we consider the work of Crompton (2015). In her study, Crompton proposes a design-based research study in which iPads are used as a means to support elementary students in their learning of the concept of angle.

In this learning context, the students used their mobile devices to identify and photograph angle-like shapes that naturally appeared in their surroundings (for example in a tree stump, in a shoe pattern, or in the corner of a table); the students then analyzed these images using dynamic geometry applications contained in their mobile devices. In this way the students analyzed whether the "natural angles" that they found in their physical environment actually conformed to the mathematical properties of an angle.

The use of mobile devices in the teaching and learning of mathematics is an emerging research area and is expanding and growing quickly. However, we must be cautious: even though mobile devices and their characteristics appear to offer vast opportunities to enrich and transform the practice of mathematics education at all levels, the introduction of these devices in the classroom also pose a number of challenges of a different nature (pedagogical, technical, and management related).

\section{MOOCS in Mathematics Education}

Massive Open Online Courses (MOOCs) offer opportunities as well as challenges for distributing knowledge from institutions. Mathematics and mathematics education are not exempt from these new initiatives (Gadanidis, 2013; McCulloch \& Rothschild, 2014). In the mathematics education context, MOOCs are "courses" because there are learning objectives, content and resources, facilitators, ways to connect and collaborate, and a beginning and an end to the learning experience. MOOCs typically use a multimedia format and resources are often short videos on specific topics. They are "massive" since there is not a limit to the number of people 
who can participate. They are "open", since typically no prerequisites exist for taking a MOOC. Furthermore, most MOOCs offer an optional evaluation process. Participants who complete the evaluation process have the option of receiving a certificate of completion, which typically requires a course fee.

MOOCs are built on the assumption of pervasive Internet access. While Internet access is not yet as widespread in developing countries as one might think, the rapid increase in the ease of access to technology suggests that it will be possible in a few years (Borba, Clarkson, \& Gadanidis, 2013). This emerging access, coupled with the lack of prerequisites for enrolment, allows MOOCs to reach a large numbers of participants. Since MOOCs allow participants to complete as much or as little of the course as they desire, MOOCs offer self-directed learning opportunities.

In some cases MOOCs facilitate a collaborative professional experience through a virtual social space for discussion, sharing ideas, resources, and opportunities for constructive feedback. Participants in these MOOCs are engaging in the learning process with others. Such collaborative learning (and even assessment) is necessary in large MOOCs, where student- instructor ratio is very high. There is not just a single path in which the network of participants and ideas is developed; engagement can use different modes (e.g. blogs, Twitter, virtual forum) to build a distributed knowledge base.

We present one example of massive professional development initiatives from Costa Rica using an adaptation of the MOOC concept. When new mathematics curricular standards or principles are generated, teachers are considered to be change agents (Llinares, Krainer, \& Brown, 2014) and a MOOC may be used to meet the challenge of implementing new curricular standards. The features of the MOOC as a course, and as being open, participatory, distributed, and a life-long networked learning environment, have been adapted for a specific context in Costa Rica, revealing the contextualized nature of MOOCs.

The goal of the adaptation of MOOCs in this initiative in Costa Rica is to support in-service teachers in the gradual implementation of the new curriculum (Ruiz, 2013). The sessions include various thinking tasks through the analysis of high quality mathematical tasks that can be solved in many ways and represented visually, emphasizing conceptual thinking. The modular teaching mini-videos (Unidad Virtual de Aprendizaje - UVA) as a complement of the design of these courses enables presenting the use of technology in mathematics teaching through the solving of real problems.

\section{Digital Library and Designing Learning Objects in Mathematics Education}

As stated in the Digital Library Manifesto (Candela et al., 2007), a digital library is potentially a virtual organization, which comprehensively collects, manages, and preserves rich digital content of all forms for its users. Obviously, digital libraries 
need a digital repository. In the context of education, digital repositories use learning objects to organize their content, which is a different method of organizing learning content than printed materials use.

Learning objects (LO) proposed by IEEE (2002) are elements of a new type of e-learning grounded in the object-oriented approach of computer science. LO can be defined as a digital entity that can be used, reused, and tagged with metadata aimed to support learning.

Accessibility, interoperability, and reusability are the main features of a learning object (Polsani, 2003). Accessibility refers to the tagging of learning objects with metadata. Interoperability refers to the method of sharing learning objects with other technology systems without the need to alter these objects. Reusability refers to the use of learning object in multiple learning environments.

Well-known learning resources in online repositories are MERLOT (Multimedia Educational Resources for Learning and Online Teaching), Wisc-Online, DRI, Khan Academy, and EBA (Digital Repository of Turkey).

The Multimedia Educational Resource for Learning and Online Teaching (MERLOT) (https://www.merlot.org/) was founded in 1997. A program of the California State University, it has been widely used internationally. MERLOT is free to use and is sustained through the support of higher education institutions from around the world.

Khan Academy (https://www.khanacademy.org) is a personalized learning resource for all ages; it offers practice exercises, instructional videos, and a personalized learning dashboard enabling learners to study at their own pace in and outside of the classroom. Their math missions guide learners from kindergarten to calculus using state-of-the-art, adaptive technology that identifies strengths and learning gaps.

What will you do in Math Today? (http://researchideas.ca) is an online open repository of resources for mathematics education, created by Gadanidis at Western University, Canada. The portal is supported by various institutions and includes a research-based math text with learning objects categorized as number, pattern and algebra, measurement and geometry, data and probability.

Current learning object studies have been focusing on quality measures, personalization, and mobile learning. Gadanidis, Sedig, and Liang (2004) analyzed the pedagogy and interface design of interactive visualization for mathematical investigation. They concluded that many interactive visualizations do not appear to be well designed, neither from a pedagogical nor from an interface design perspective. Studies have shown that quality assurance of the LORs is a significant factor when predicting the success of repositories (Clements, Pawlowski, \& Manouselis, 2015).

Students today often turn to online mathematics learning resources, such as digital libraries and learning objects before consulting a teacher or a textbook. As mathematics educators, we need to develop and organize these resources in such a way that they facilitate access and foster conceptual understanding. 


\section{Using Technology in Collaborative Learning}

Opinions have been aired that technology enhanced learning (TEL) has not succeeded in revolutionizing education and the learning process (Chatti, Agustiawan, Jarke, \& Specht, 2010). One reason that is suggested is that most current initiatives take a technology-push approach in which learning content is pushed to a pre-defined group of learners in a closed environment A fundamental shift toward a more open and student-pull model for learning is needed - a shift toward a more personalized, social, open, dynamic, and knowledge-pull model as opposed to the one-size fits all, centralized, static, top-down, and knowledge-push models of traditional learning.

A virtual learning environment (VLE) or learning management system (LMS) is a Web-based platform for courses of study, usually within educational institutions. LMSs (or VLEs) could allow participants to be organized into groups; present resources, activities and interactions within a course structure; provide for the different stages of assessment; report on participation; and have some level of integration with other institutional systems.

Personal learning environments (PLEs) can be viewed as the latest step in an alternative approach to e-learning. The concept has been developed in parallel to that of an LMS - the difference being that a LMS is course wide (or institution wide) while a PLE is individual. PLE's may consist of a number of subsystems, such as a desktop application and one or more web-based services. A PLE would integrate formal and informal learning, such as using social networks, and use collaboration possibilities, such as small groups or web services, to connect a range of resources and systems in an individual space.

Related to the concept of a PLE is the idea of a personal learning network (PLN). Whereas PLEs are the tools, artifacts, processes and physical connections that allow learners to control and manage their learning, PLNs extend this framework to include an informal learning network of people to connect with for the specific purpose of learning. In a PLN there is an understanding among participants that the reason they are connecting is for the purpose of active learning (Lalonde, 2012).

In the early 21 st century, the creation of rich learning mashups (mostly web applications that integrate complementary elements from different sources) currently associated with collaborative learning, resulted from advances in digital media. Wild, Kalz, and Palmér (2010) describe mash-ups as "the frankensteining of software artefacts and data" (p. 3). They describe the development of a technological framework enabling students to build up their own personal learning environments by composing web-based tools into a single-user experience, getting involved in collaborative activities, sharing their designs with peers, and adapting their designs to reflect their experience of the learning process. Wild et al. (2010) also introduced the term Mupple (Mash-up Personal Learning Environment). 
Mupples typically consist of distributed web-applications and services that support individual and collaborative learning activities in both formal and informal settings.

PLEs and PLNs have been extensively implemented in teaching computer science students in particular. In mathematics education these approaches have not really been researched sufficiently. Harding and Engelbrecht (2015) investigated PLN clusters that spontaneously formed among students in two fields of studymathematics and computer science. Students in a cluster use a number of tools to communicate and learn while using social media, mobile phone technology and learning management systems, among other platforms for learning purposes.

Too little has been done with using the concepts of PLEs and PLNs in the teaching of mathematics - a conceptual subject in which we know that collaboration increases the chances of students developing an understanding of the concepts.

\section{Math-for-Teachers as a Blended Course: An Elementary Teacher Education Case from Canada}

Blended learning, which combines both online and face-to-face classroom experiences, is becoming common practice in education at all levels (LaFee, 2013; Owen $\&$ Dunham, 2015). The online experience can offer students opportunities to revisit and extend ideas and concepts they encountered in the face-to-face classroom. It can also be used as way to "flip" the classroom experience by giving students opportunities to encounter, explore, and reflect on ideas and concepts before they engage with them in the face-to-face classroom. The flipped classroom model also allows instructors more face-to-face time "to dig deeper into the 'why' of the mathematics" (Ford, 2015, p. 370). The online material created by teachers to support a blended model offers some advantages: it can easily be updated to be current and to better match student needs that arise; it can be shared among teachers to provide professional development; it gives parents a window into their children's learning (Ford, 2015; Wilson, 2013).

The mathematics-for-teachers activities are the same mathematics activities we have been developing in K-8 research classrooms for approximately a decade in Canada and in Brazil (Gadanidis \& Borba, 2008; Gadanidis, 2012). The online component of our blended program (www.researchideas.ca/wmt) serves a number of purposes: it is a form of research dissemination; it is a collection of math-for-teachers activities; it is a resource freely available to teachers in the field to use in their classrooms; and it is a set of math-for-teachers courses that we offer through the Fields Institute for Research in Mathematical Sciences. The online resource contains a wide variety of content. 


\section{Conclusions and Perspective}

It seems safe to say that technological change will continue and likely increase in pace. In this context, we can fall into a pattern of chasing the latest innovation rather than charting our own direction, focusing on "what is the latest technology" rather than on "what is worth researching?"

Mobile technology, PLNs, digital learning objects and other artifacts are "stretching" the classroom, transforming the classroom to the extent that it can hardly be recognized as such. A significant part of pre-service mathematics teacher education is done online in many countries (e.g. Brazil, Costa Rica) in that students only meet when writing tests and a few non-mandatory face-to-face meetings (Ruiz, 2013). In this scenario, the regular classroom no longer serves as locus for education. Couches, chairs, tables at students' houses and cafés are the "new classrooms". Flipped classrooms change the notion of what is in and outside of the classroom and also change the roles of students and teachers.

As pointed out in the paper, PLEs and social networks such as Facebook, may make it even more difficult to keep the traditional distinction between "inside the classroom" and "outside the classroom" or between "study time" and "leisure time". Different blends are being forged into face-to-face education and online distance education in such a way that it will be interesting to see how much this distinction will be blurred in a few years time.

The trends of development discussed in this paper highlight five important issues in the intersection of e-learning and mathematics education that might serve as contexts for investigating "what might be":

1. Student access to mobile technologies creates a student-mathematics relationship that is not yet widely embraced by mathematics educators, that disrupts the traditional flow of mathematics knowledge from teacher to student, and that is not well understood from a research perspective.

2. The potential of MOOCs to disrupt the institutional and hierarchical nature of traditional education, offering students opportunities to access courses without prerequisites, without fees (unless they require a record of course completion), and the potential of MOOCs to affect access to and the quality of mathematics education is not well understood.

3. The availability of online mathematics learning resources (as the digital libraries and learning objects) means that many students now turn to these resources before they consult a teacher or a textbook, and this raises questions about how the resources are organized to in order to facilitate access and how they are designed pedagogically to foster conceptual understanding.

4. The collaborative and social networking affordances of current technologies raise questions about the design and use of learning management systems as well as personal learning environments and networks.

5. Teacher use of blended learning to extend and supplement classroom learning with online exploration and discussion or to employ a flipped classroom model to make the classroom a place for extension and elaboration rather than direct instruction raises questions about the need to research the various models used. 
These five themes are not independent. Firstly, we notice issues related to the nature of new types of mobile/digital technological means, favouring the access to knowledge/information of mathematics and mathematics education and modifying the nature of interaction students-knowledge-teacher-context. How do we use the new technological means when the objectives are related to mathematics and mathematics education learning? Secondly, we notice issues related to how mathematics or knowledge from mathematics education is considered/organized in this new context (digital libraries, digital repertories, learning objects and inclusive the MOOCS). Finally, we identify issues related to the nature of the interaction among persons and between persons and mathematical and mathematics education knowledge when they are learning.

These three cross-cutting aspects define two dimensions in the research in this field: (i) when the focus is on how the new mobile/digital technological means define new forms of organizing knowledge and facilitating the access to knowledge (the learning objects, MOOCs, digital library, digital repository and so on), and (ii) when the focus is on how the use of new mobile/digital technological means determines the nature of the interactions between humans, and between humans and knowledge in the learning contexts. So, these dimensions generate epistemological issues (about the nature of mathematical and mathematics education knowledge) and issues about social and individual aspects of learning, as well as issues about the role of interaction in this learning.

These trends that we emphasize and describe belong to the fourth phase in the development of using digital technology in mathematics education (as mentioned in the introduction). This phase is shaped by fast Internet and integrated with various procedures and practices from the other three phases, as well as from the history (going back over 30 years) of attempting to include digital technology in mathematics education. Most students have already decided that cellular phones make up part of their lives inside or outside the classroom. These devices are definitely part of the collective of "students-with-mobile-phones". Other technologies such as paper and pencil, as well as computer software are also accepted in this collective, but for the most part, the current generation at schools and universities do not see the world without mobile technology.

\section{References}

Bicudo, M. A. V. (2014). Meta-análise: seu significado para a pesquisa qualitativa [Meta-synthesis: Its meaning in the qualitative research]. Revemat: Revista Eletrônica de Educação Matemática, 9(0), 7-20. doi:10.5007/1981-1322.2014v9nespp7

Borba, M. C., Askar, P., Engelbrecht, J., Gadanidis, G., Llinares, S., \& Sánchez Aguilar, M. (2016). Blended learning, e-learning and mobile learning in mathematics education. ZDM Mathematics Education, 48(5), 589-610. doi:10.1007/s11858-016-0798-4

Borba, M. C., Clarkson, P., \& Gadanidis, G. (2013). Learning with the use of the Internet. In M. A. (Ken) Clements, A. J. Bishop, C. Keitel, J. Kilpatrick, \& F. K. S. Leung (Eds.), Third international handbook of mathematics education (pp. 691-720). New York: Springer. doi:10. 1007/978-1-4614-4684-2_22 
Borba, M. C., \& Llinares, S. (2012). Online mathematics teacher education: overview of an emergent field of research. ZDM-The International Journal on Mathematics Education, 44(6), 697-704. doi:10.1007/s11858-012-0457-3

Borba, M. C., Malheiros, A. P. S., \& Zulatto, R. B. A. (2010). Online distance education (1st ed.). Rotterdam: Sense Publishers.

Borba, M. C., Scucuglia, R. R. S., \& Gadanidis, G. (2014). Fases das tecnologias digitais em educação matemática: sala de aula e internet em movimento [Phases of digital technologies in mathematics education: The classroom and the internet in motion] (1st ed.). Belo Horizonte: Autêntica.

Candela, L. et al. (2007). The DELOS digital library reference model: foundation for digital libraries, version 0.96. Resource document. European Commission within the Sixth Framework Programme. http://delosw.isti.cnr.it/files/pdf/ReferenceModel/DELOS_DLReferenceModel_096.pdf

Chatti, A. C., Agustiawan, M. R., Jarke, M., \& Specht, M. (2010). Toward a personal learning environment framework. International Journal of Virtual and Personal Learning Environments, 1(4), 66-85. doi:10.4018/jvple.2010100105.

Clements, M. A. K., Bishop A. J., Keitel, C., Kilpatrick, J., \& Leung, F. K. S. (Eds.). (2013). Third international handbook of mathematics education. New York: Springer. doi:10.1007/978-14614-4684-2

Clements, K., Pawlowski, J., \& Manouselis, N. (2015). Open educational resources repositories literature review-Towards a comprehensive quality approaches framework. Computers in Human Behavior, 51(Part B), 1098-1106. doi:10.1016/j.chb.2015.03.026

Crompton, H. (2015). Understanding angle and angle measure: A design-based research study using context aware ubiquitous learning. International Journal for Technology in Mathematics Education, 22(1), 19-30. doi:10.1564/tme_v22.1.02

Crompton, H., \& Traxler, J. (Eds.). (2015). Mobile learning and mathematics. Foundations, design and case studies. Florence, KY: Routledge.

D'Ambrosio, U., \& Borba, M. C. (2010). Dynamics of change of mathematics education in Brazil and a scenario of current research. ZDM-The International Journal on Mathematics Education, 42(3), 271-279. doi:10.1007/s11858-010-0261-x

Engelbrecht, J., \& Harding, A. (2005a). Teaching undergraduate mathematics on the Internet. Part 1: Technologies and taxonomy. Educational Studies in Mathematics, 58(2), 235-252. doi:10. 1007/s10649-005-6456-3

Engelbrecht, J., \& Harding, A. (2005b). Teaching undergraduate mathematics on the Internet. Part 2: Attributes and possibilities. Educational Studies in Mathematics, 58(2), 253-276. doi:10. 1007/s10649-005-6457-2

Ford, P. (2015). Flipping a math content course for pre-service elementary school teachers. Primus, 25(4), 369-380. doi:10.1080/10511970.2014.981902

Franklin, T., \& Peng, L.-W. (2008). Mobile math: math educators and students engage in mobile learning. Journal of Computing in Higher Education, 20(2), 69-80. doi:10.1007/s12528-0089005-0

Gadanidis, G. (2012). Why can't I be a mathematician? For the Learning of Mathematics, 32(2), $20-26$.

Gadanidis, G. (2013). Designing a Mathematics-for-All MOOC. In T. Bastiaens, \& G. Marks (Eds.), Proceedings of e-learn: World conference on e-learning in corporate, government, healthcare and higher education, 2013 (pp. 704-710). Chesapeake, VA: Association for the Advancement of Computing in Education (AACE). http://www.editlib.org/p/114923. Accessed July 28, 2015.

Gadanidis, G., \& Borba, M. (2008). Our lives as performance mathematicians. For the Learning of Mathematics, 28(1), 44-51.

Gadanidis, G., Sedig, K., \& Liang, H. N. (2004). Designing online mathematical investigation. Journal of Computers in Mathematics and Science Teaching, 23(3), 275-298.

Harding, A., \& Engelbrecht, J. (2015). Personal learning network clusters: A comparison between mathematics and computer science students. Journal of Educational Technology and Society, $18(3), 173-184$. 
Holubz, B. J. (2015). Mobilizing mathematics. Participants' perspectives on bring your own device. In H. Crompton \& J. Traxler (Eds.), Mobile learning and mathematic. Foundations, design, and case studies (pp. 213-222). Florence, KY: Routledge.

IEEE Learning Technology Standards Committee. (2002). Draft standard for learning object metadata. Resource document. IEEE. http://129.115.100.158/txlor/docs/IEEE_LOM_1484_ 12_1_v1_Final_Draft.pdf. Accessed January 29, 2016.

LaFee, S. (2013). Flipped learning. The Education Digest, November Issue, 13-18.

Lalonde, C. (2012). How important is Twitter in your personal learning network? eLearn Magazine. September 2012. http://elearnmag.acm.org/featured.cfm?aid=2379624. Accessed August 1, 2015.

Larkin, K., \& Calder, N. (2015). Mathematics education and mobile technologies. Mathematics Education Research Journal. doi:10.1007/s13394-015-0167-6.

Llinares, S., Krainer, K., \& Brown, L. (2014). Mathematics teachers and curricula. In S. Lerman (Ed.), Encyclopedia of mathematics education (pp. 438-441). New York: Springer. doi:10. 1007/978-94-007-4978-8_111

McCulloch, R., \& Rothschild, L. P. (2014). MOOCs: An inside view. Notices of the AMS, 61(8), 2-8. doi:10.1090/noti1147

McLuhan, M. (1964). Understanding media: The extensions of man. New York: McGraw Hill.

NGSS Lead States. (2013). Next generation science standards: For states, by states. http://www. nextgenscience.org

Owen, H., \& Dunham, N. (2015). Reflections on the use of iterative, agile and collaborative approaches for blended flipped learning development. Education Sciences, 5(2), 85-105. doi:10.3390/educsci5020085

Polsani, P. R. (2003). Use and abuse of reusable learning objects. Journal of Digital Information, 3 (4). http://journals.tdl.org/jodi/article/viewArticle/89/88

Ruiz, A. (2013). La reforma de la educación matemática en Costa Rica. Perspectiva de la praxis [The mathematics education reform in Costa Rica. Perspective of praxis]. Cuadernos de Investigación y Formación en Educación Matemática, Year 8, Special Number. http://revistas. ucr.ac.cr/index.php/cifem/article/view/11125

Schrage, M. (2001). The relationship revolution. http://web.archive.org/web/20030602025739/, http://www.ml.com/woml/forum/relation.htm. Accessed July 12, 2008.

White, T., \& Martin, L. (2014). Mathematics and mobile learning. TechTrends, 58(1), 64-70. doi:10.1007/s11528-013-0722-5

Wijers, M., Jonker, V., \& Drijvers, P. (2010). MobileMath: exploring mathematics outside the classroom. ZDM-The International Journal on Mathematics Education, 42(7), 789-799. doi:10.1007/s11858-010-0276-3

Wild, F., Kalz, M., \& Palmér, M. (Eds.). (2010). Proceedings of the 3rd Workshop on Mashup Personal Learning Environments. Barcelona, Spain. http://ceur-ws.org/Vol-638/. Accessed February 14, 2014.

Wilson, S. G. (2013). The flipped class. A method to address the challenges of an undergraduate statistics course. Teaching of Psychology, 40(3), 193-199. doi:10.1177/0098628313487461

Yerushalmy, M., \& Botzer, G. (2011). Guiding mathematical inquiry in mobile settings. In O. Zaslavsky, \& P. Sullivan (Eds.), Constructing knowledge for teaching secondary mathematics (pp. 191-207). New York: Springer. doi:10.1007/978-0-387-09812-8_12

Open Access Except where otherwise noted, this chapter is licensed under a Creative Commons Attribution 4.0 International License. To view a copy of this license, visit http://creativecommons. org/licenses/by/4.0/.

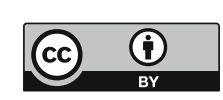

